\title{
SALVARSE SALVANDO AL PRÓJIMO. LA OBRA PÍA DE FRANCESC DE VERÍ
}

\section{SAVING ONESELF BY SAVING ONE'S NEIGHBOUR. THE PIOUS LEGACY OF FRANCESC DE VERÍ}

\author{
Miguel José DeYÁ BAUZÁ \\ Universitat de les Illes Balears-IEHM
}

Recibido: 13/03/2020 Aceptado: 22/04/2020

\section{RESUMEN}

El rescate de cristianos cautivos en tierra de musulmanes es una constante en el Mediterráneo cristiano de los siglos XVI y XVII. El legado testamentario para la redención de esos cautivos no es extraño, aunque cada uno puede presentar particularidades propias. El presente estudio de caso nos ilustra sobre la mentalidad del testador, la ejecución de este tipo de legados e, incluso, su visión de la sociedad del momento.

Palabras clave: cautivos, purgatorio, redención, rescate.

\footnotetext{
* Este trabajo ha sido financiado por la Comunidad Autónoma de las Islas Baleares por medio de la Direcció General de Política Universitària i Recerca con fondos procedentes de la Ley del Impuesto sobre Estancias Turísticas (2017-006) (Proyecto PRD2018/17).
} 


\section{ABSTRACT}

The rescue of Christian captives in Muslim lands was a constant in the Christian Mediterranean of the 16 th and 17 th centuries. Testamentary bequests for the redemption of these captives is not uncommon, although each one may have its own particularities. This case study illustrates the mentality of the testator, the execution of this type of bequest and even his vision of the society of the time.

Keywords: captives, purgatory, redemption, rescue

\section{INTRODUCCIÓN}

Efectivamente, tal y como se deduce del título de este monográfico, la espiritualidad en el Renacimiento y en el Barroco se nos presenta de numerosas formas. Desde la perspectiva católica las buenas obras no son sólo una obligación moral, sino una forma de ganarse la vida eterna. Si estas buenas obras, además, sirven para salvar a otros cristianos del peligro de renegar entenderemos la importancia del fenómeno redencionista en sociedades muy próximas geográficamente a tierra de moros. Rescatar al cautivo era, de hecho, una obra de misericordia que podía reducir tu estancia en el purgatorio, pero era además un peligro político, pues el pago del rescate alimentaba al enemigo político, religioso y cultural. Este último aspecto nos puede explicar que la autoridad política, empezando por la propia Corona, intentara controlar esos contactos o al menos vehicularlos a través de mecanismos concretos, preferentemente determinadas órdenes religiosas, fundamentalmente mercedarios y trinitarios $\mathrm{o}$, en ocasiones, los franciscanos u otras.

Pocos ejemplos más claros de la dimensión espiritual del rescate de cautivos que el legado de una obra pía destinada precisamente a esta finalidad. Las consecuencias no podían ser más benéficas. El otorgante y/o sus parientes ganaban una reducción de su estancia en el Purgatorio y se evitaba el peligro de renegar del cautivo, especialmente grave si se trataba de niños o menores de edad, pues éstos con más facilidad se podían convertir en soldados del Islam. Sin embargo, en ocasiones el cumplimiento de las disposiciones del otorgante eran difíciles, por lo que tan importante como el análisis de la obra pía es el análisis de su ejecución. Para el caso mallorquín contamos con un ejemplo que puede elevarse a estudio de caso: el de la obra pía de Francesc de Verí. 


\section{FRANCESC DE VERÍ Y SU OBRA PÍA.}

De todos es conocido la envergadura del fenómeno del cautiverio en el Mediterráneo del siglo XVI. Más raro ha sido el considerar el rescate de cautivos en peligro de renegar llevado a cabo de forma individual como una peculiar forma de espiritualidad y de ganarse en cielo. Más allá de la tradicional forma de rescate por medio de mercedarios y trinitarios y, en menor medida, por parte de otras órdenes religiosas, también se dieron iniciativas de tipo particular ligadas no sólo al rescate de familiares y amigos, lo que es natural y bien conocido, sino al rescate de cristianos como una obra de caridad y misericordia, convirtiéndose así en una manifestación religiosa, en una forma de espiritualidad y de perdón, si quiera parcial, de los pecados del rescatador. La manda pía se convierte así en un instrumento para conseguir el fin material al que acabamos de referirnos (el rescate del cristiano cautivo) y a la vez del espiritual (una ayuda para la salvación de la propia alma). El caso de Mallorca nos ofrece un ejemplo muy claro de esta peculiar forma de espiritualidad muy ligada, por otra parte, a las circunstancias políticas, sociales y culturales del momento: la obra pía de Francesc de Verí, presbítero y donzell de Mallorca ${ }^{1}$. Era nuestro personaje miembro de la prestigiosa familia de los Verí, llegada a Mallorca en el siglo $\mathrm{XIII}^{2}$. Su tío, Ramon de Verí, había sido Bailío en Mallorca de la orden de San Juan de Jerusalén ${ }^{3}$. Dictó testamento Francesc de Verí ante el notario Melchor Sans el 22 de febrero de $1595^{4}$. Se insertaba en dicho testamento una manda pía para el rescate de cautivos ${ }^{5}$.

Entre las cláusulas que debían regir la manda pía de Francesc de Verí, algunas bien curiosas, podemos destacar:

1 En el Reino de Mallorca el tratamiento de donzell es el propio del caballero no armado, denotando, por tanto, la pertenencia del sujeto al primero de los estamentos del Reino.

2 Joaquín M. Bover, Nobiliario Mallorquín (Palma: José J. de Olañeta. Bover, 1996), 418. Diversos miembros de la familia participaron a favor de Juan II en la Guerra Civil Catalana, ocupando desde el siglo XV en diversas ocasiones el cargo de Jurat por el estamento de los ciudadanos, el segundo de los estamentos encuadrados en el brazo noble y al cual -a diferencia de los caballeros- se permitía mercadear. Bartomeu de Verí, jurista, obtuvo patente de nobleza de Juan II, desarrollando diversos cargos de confianza real, entre ellos el de regente del Consejo de Aragón. Véase Antonio Planas, "Los juristas mallorquines del siglo XVI", Memòries de l'Acadèmia Mallorquina d'Estudis Genealògics, Heràldics $i$ Històrics 10 (2000): 67.

3 Archivo Capitular de Mallorca (A.C.M.), 14.518.

4 A.C.M., 14.518 , f. 7.

5 Ad laudem, gloriam et honorem Sanctisima Trinitatis, Patris, et Filius et (E)spiritus Sancti et in favorem, propagationem et aumentum Sacrosante Religionie.... ac fidelium christianorum penes infidelis in tam dura servitude et captivitate detentorum cum magno periculo abnegandi dictam Sacrosanctam Fidem Catholicam. 
$\left.1^{\circ}\right)$ Una parte de las rentas que recibía el testador y que a partir de su muerte debían consignarse al rescate de cautivos eran censales derivados de préstamos a la Universidad del Reino, es decir deuda pública. Así, por este mecanismo, los intereses que abonaba el Reino como interés de la deuda pública servirían finalmente para la redención de cautivos ${ }^{6}$.

$2^{\circ}$ ) Otra partida que debía destinarse al mismo objetivo era la de 36 libras anuales que Verí cobraba del Colegio de la Mercadería sobre la recaudación del diner del moll, impuesto indirecto sobre el comercio exterior de Mallorca, censo constituido en junio de 1591.

$3^{\circ}$ ) Se le añadía una renta anual de 5 libras, 2 sueldos y 3 dineros, parte de un censo de mayor cuantía, que pagaba anualmente la Universidad y que se le había cedido por parte de su hermano Antonio como heredero de su padre.

$\left.4^{\circ}\right)$ Las rentas procedentes de las arcas del Reino que debían dedicarse al rescate se completaban con todo un conjunto de censos que rentaban anualmente $14011.17 \mathrm{~s} .9 \mathrm{~d}$. y había comprado a particulares en lo que de hecho funcionaba como un mercado secundario de deuda de renta fija.

A estas partidas hay que unir otras 365 libras, hasta llegar a las 1.000 libras anuales, con censos que pagaban particulares por cargas que gravaban sus propiedades rurales o urbanas.

Tras citar las rentas que debían financiar la manda pía, en el documento constitutivo de la misma se procedía a recordar su objetivo, el rescate de cautivos en peligro de renegar, siendo este último sintagma importante para entender la mentalidad del testador y la finalidad de la manda pía. Se insistía en que a ese objetivo y no a otro debía dedicarse el caudal de la manda pía en record de Crist que ab sa preciosíssima sang redimi los homens de la captivitat del pecat y esclavonia del dimoni. Se establecía, así, en la mente del testador una conexión entre la redención de cautivos y la obra redentora por excelencia, la de Cristo a la humanidad toda. Llegaba Francesc de Verí incluso a prohibir explícitamente que el caudal de la manda pía se destinara a la Santa Cruzada o a la Cámara o Sede Apostólica, indicando que si se intentaba alguna maniobra al respecto se

6 Las rentas censuales que pagaba el Reino y se consignaban a la finalidad citada eran:

- 120 libras anuales fruto de un empréstito de 705 libras al $17 \%$ constituido con fecha 18 de febrero de 1592 .

- 150 libras por empréstito de 882 libras al 17\% constituido con fecha 26 de julio de 1591.

- 120 libras por empréstito constituido el 6 de septiembre de 1590 sobre los ingresos del quint del vi, impuesto indirecto sobre el consumo de vino.

- 30 libras por empréstito de 176 libras, 10 sueldos al 17\% constituido el 22 de noviembre de 1590. 
considerase revocada la manda pía y el caudal y propiedad de la misma se transfiriera a su pariente varón más próximo estableciéndose así un fideicomiso.

A la importante suma legada, mil libras anuales, le correspondía una ejecución que suponía una verdadera operación logística que pasaba por los siguientes puntos:

$1^{\circ}$ ) Tras la aceptación del cargo de administrador de la manda pía por parte del Cabildo de la Catedral de Mallorca, cada tres años éste procedería a la compra de paños, mantas y demás mercancías para su venta en Argel u otros lugares de dominación musulmana para proceder a la redención de cristianos, preferentemente mallorquines, financiada con la venta de dichos artículos. Recuérdese que hasta entrado el siglo XVII no se permitió la salida de moneda de tierras hispánicas para el rescate de cautivos, por lo que debía procederse a hacerlo por medio de la venta de mercancías en las tierras de presidio ${ }^{7}$.

$\left.2^{\circ}\right)$ El Cabildo debía nombrar a sacerdote o religioso para dirigir la redención de los cautivos, siendo imperativo que fuera natural del Reino de Mallorca.

$3^{\circ}$ ) Tres meses antes de la salida del barco se anunciaría la misma y su finalidad en todas las iglesias de Mallorca para que los parientes de cautivos lo notificaran a los administradores de la manda pía. En la documentación, aspecto no menor, se emplea en no pocas ocasiones el concepto de esclavo para hacer referencia a los cautivos mallorquines en manos de infieles. Se trata de un detalle importante si se tiene en cuenta la importancia que los esclavos habían tenido en la Edad Media mallorquina e incluso su existencia, ya mucho menor cuantitativamente, en los momentos en que se redactó el testamento y la manda pía. Efectivamente, tras los últimos trabajos de Antoni Mas resulta evidente que en la Mallorca de la época la palabra esclavo no sólo significaba falto de libertad, sino que también y quizás más aún implicaba de forma implícita estar en un ámbito geográfico no propio y, por tanto, ser un elemento exógeno a la sociedad en la que uno se hallaba implantado ${ }^{8}$.

$\left.4^{\circ}\right)$ Pocos días antes de la salida del barco destinado a la redención de cautivos se haría una prédica general en la Catedral de Mallorca, solicitándose al Obispo recomendara la presencia de toda la ciudad; en dicha prédica se expondrían a la concurrencia los benéficos efectos de la empresa, insistiendo en que se trataba de rescatar cristianos pobres cautivos, buscando así donativos para la

7 María Dolores Torreblanca, "Redención de cautivos en la época de Felipe II", en Felipe II y su tiempo. Actas de la V Reunión Científica. Asociación Española de Historia Moderna, ed. José L. Pereira et Jesús M. González (Cádiz: Universidad de Cádiz- Asociación de Historia Moderna, 1999), 215.

8 Antoni Mas, Esclaus i catalans (Palma: Lleonard Muntaner, Editor) 2005. 
misma. Acabada la ceremonia dos canónigos y otros dos religiosos recorrerían la ciudad con alguno de los paños comprados para la redención con objeto de mover más a la piedad de la población Se establecía del mismo modo que los párrocos de las villas llevasen a cabo en su localidad idénticas funciones.

$5^{\circ}$ ) Tras ello, los administradores de la manda pía iniciarían un sesudo examen de cada petición considerando de quina edat és lo esclau, si és pobre o ric, si és home o dona, si ha molt temps que està pres $i$ de quant rescat és $i$ que té aplegat o promès per son rescat $i$ lo que lo pot faltar i totes aquestes circumstàncies s'escriuran per valerse aprés en la ocasió.

Se añadía que como el objetivo era rescatar al mayor número posible de cautivos, preferentemente mallorquines, convenía que para cada rescate se pudiera disponer de los bienes de estos o de lo que se hubiera podido recaudar por otras vías distintas a la manda pía que aquí nos ocupa.

Se establecía del mismo modo un orden de prelación por lo que respecta a las personas a rescatar. En primer lugar, se situaban los miembros de la familia Verí y dentro de ellos según el grado de parentesco con el testador. En segundo lugar, se colocaban los que hubiesen sido criados de su tío Ramón de Verí, quien había sido Bailío en Mallorca de la orden de San Juan de Jerusalén y al cual el testador se hallaba muy unido. Posteriormente sus propios criados y luego los de otros miembros de la familia Verí según su edad y preferidos siempre los criados mallorquines sobre los foráneos ${ }^{9}$, aunque los criados forasteros tendrían prioridad sobre los cautivos mallorquines no ligados a su casa. Del mismo modo los niños y mujeres serían preferidos para el rescate sobre los hombres atendiendo al su mayor peligro de renegar ${ }^{10}$. Posteriormente se determinaba la dedicación preferente de la manda pía a los cautivos pobres, perquè los qui són richs no tenen necessitat de menjar lo pa dels pobres de Jesucrist. ${ }^{11}$ Por lo que

9 La preferencia de mallorquines sobre forasteros la encontramos en legados concretos de etapas anteriores como es el caso del dispuesto por Joan de Conilleres en 1477 por un montante de 25 libras o por Ramon de Salelles en 1345 por valor de 100 1. Véase Antoni Mas, Llengua, terra, patria i nació. L'evolució de la consciència lingüistica i etnocultural entre elscristians de l'illa de Mallorca (segles XIV-XVII) (Palma: Ed Documenta, 2020), 66, 89.

10 Las referencias a la preferencia de los niños a la hora del rescate y su mayor peligro de renegar son todo un clásico en este tema. No olvidemos que la conversión de los niños era la preferida por parte de los musulmanes, empleando en no pocas ocasiones a los muchachos convertidos como importante pieza en la lucha militar contra los cristianos. Véase Torreblanca, "Redención de cautivos en la época de Felipe II", 214.

11 Martínez Torres vincula esa especial preocupación por el rescate de mueres, niños, ancianos y pobres demás desvalidos - al contrario de lo que ocurría en la Edad Media- a una creciente adopción en España y América los postulados aprobados en el Concilio de Trento. Véase José Antonio Martínez Torres, Prisioneros de los infideles. Vida y rescate de los cautivos cristianos en el Mediterráneo musulmán (siglos 
respecta a los cautivos mallorquines oriundos de la part forana (la porción de la isla formada por las villas, es decir la totalidad de la misma excepto la capital y su término) el testador establecía la preferencia de los nacidos en Pollença por su singular aprecio a esa localidad y sus gentes. En ausencia de cautivos mallorquines tendrían preferencia los naturales de la Corona de Aragón.

Efectuada la redención, el barco debía volver a Mallorca, donde los rescatados -mallorquines o forasteros- debían dirigirse inmediatamente a la Catedral en acción de gracias a la Virgen y desde allí al templo de Nuestra Señora del Socorro. En un plazo no superior a los tres días los rescatados debían confesar y comulgar en la capilla de San Pedro de la Catedral (ábside de la nave lateral lindante con el sitio de la Epístola) donde el testador estaría enterrado (nótese el lugar preferente de la sepultura); allí se realizaría un sermón pidiendo por la propagación de la Fe Católica, por el alma del fundador de la manda pía y la de sus parientes y por la de todos los participantes en la empresa ya fuera mediante a donativos o con su colaboración personal.

\section{LA EJECUCIÓN DE LA MANDA PÍA}

Los aspectos formales del cumplimiento de la voluntad del testador eran de difícil cumplimiento (destinar un barco específico a la operación, prédicas anteriores a su salida...) Aún así el Cabildo aceptó el cargo de administrador de la manda a la muerte de Francesc de Verí1 ${ }^{12}$. El período en que se inicia la ejecución de la obra pía, tras la muerte de su fundador, es de especial relevancia, pues la última década del quinientos y primera de la centuria posterior es el período de mayor impacto de las capturas de cristianos por parte de naves berberiscas ${ }^{13}$. Pronto aparecieron los problemas. Con fecha 27 de Julio de 1596 el Cabildo al constatar no poderse practicar la disposición e ordre d'anar a Alger, ${ }^{14}$ decidió modificar las instrucciones contenidas en la manda pía y que ésta fuera administrada según las instrucciones señaladas por otro Verí, el que en esos momentos ocupaba el cargo de Bailío de la Orden de San Juan de Jerusalén en Mallorca. En conclusión, en septiembre y octubre de ese mismo año se llevaron a cabo los primeros pagos a cuenta de la manda pía y a favor de antiguos cautivos que

XVI-XVII) (Barcelona: Ed. Bellaterra, 2004), 77, aunque en este caso concreto se mantenía la prelación de los miembros de la familia Verí, entendida en un sentido lato y con inclusión de los criados.

12 A.C.M., 14.518 , f. $18 \mathrm{v}$.

13 Giuseppe Bonaffini, Sicilia e Tunisia nel secolo XVII (Palermo-Sao Paulo: Ila-palma, 1984), citado por Martínez Torres, Prisioneros de los infideles, 47.

14 A.C.M., 14.518, f. 15. 
habían ya sido rescatados y vueltos a Mallorca, en concreto se pagaron 25 libras a Pere Sansó, de Manacor ${ }^{15}$, y otro tanto Joan Escolà y Jeroni Vicens de Pollença. En ese mismo período se otorgaba una ayuda a Antoni Fe y Gabriel Far, aún no rescatados, de 50 1. a cada uno ${ }^{16}$; todo ello según el criterio del citado Bailío. Se argumentaba que el fundador de la manda pía había establecido en la misma que el criterio de aquél fuera atendido en la ejecución correspondiente.

No quedaron aquí los cambios. Desde 1596 las ayudas se otorgaron tanto a cautivos ya rescatados como a personas con parientes por rescatar. Con estas condiciones, a partir del 25 de septiembre hasta fin de año se gestionó el rescate de seis personas, con un coste de 200, una de ellas de Pollença (JeroniVicens), siguiendo los deseos del testador. En el año 1597 se gestionó el rescate de un mínimo de diez personas, pues en un asiento se dice que son varios, pero no se concreta el número, con un coste mínimo de 345 para todo el año. En 1598 se gestionó el rescate de cuatro personas, con un coste de 110 libras. En 1599 se gestionó el rescate de entre 20 y 23 personas, pues en un caso se recoge el rescate de tres personas sin indicar que sea a cuenta de esta obra pía, aunque con toda probabilidad lo son habida cuenta de la cantidad que se dedica a ello, 50 libras a cada individuo, frente a lo que ocurre en las ayudas al rescate de las limosnas generales de la Catedral para cautivos que eran habitualmente de cinco libras. El coste de los rescates para ese año de 1599 sería de un mínimo de 925 libras.

Vale la pena citar, siquiera someramente, algunos de los rasgos que refleja la documentación derivada de la ejecución de la obra pía en los años inmediatamente posteriores a la muerte de Francesc de Verí

$\left.1^{\circ}\right) \mathrm{Al}$ menos en estos primeros años la decisión de a quién conceder la ayuda para el rescate se tomaba entre el Bailío Verí y el Canónigo Garau, delegado del Cabildo para la administración de la manda pía ${ }^{17}$.

$\left.2^{\circ}\right)$ La ayuda concedida a cuenta de la manda pía de Francesc de Verí era compatible con otras ayudas. Así en 1597 a cuenta de la referida manda pía se dieron a Petro Grech 50 1. a las que se añadieron otras 51 . procedentes de la de Caterina Pachs ${ }^{18}$.

$3^{\circ}$ ) Las ayudas se concedían, como ya se ha señalado, tanto a los que ya habían sido rescatados como a los que seguían cautivos. En este último caso y al menos en algunas ocasiones los parientes del cautivo debían presentar avales. 
Es este el caso acontecido en Julio de 1597, cuando se concedieron a cuenta de la obra pía 50 1. a Elisabeth Quintana para el rescate de su hijo Jeroni Torres, recogiéndose que, como el rescate ya había sido pactado, dicha Elisabeth presentaba como fiadores al zapatero P. Horrach y al pelaire Joan Saqueres por si el rescaten no se producía, en cuyo caso debían devolverse las $501 .{ }^{19}$ Caso similar lo localizamos en el mismo año referido a magistro Antoni Garcia, músico, al que se dieron 50 1l. por el rescate de Cosme García con la condición de que debía devolverlos si el recate no se consumaba ${ }^{20}$. En casos de pobreza del cautivo no se exigían esos avales, pero sí se explicitaba que el rescate debía llevase a cabo en el plazo de un año, aunque en algunos casos se concedía una prórroga por un año más.

$4^{\circ}$ ) La ayuda económica se hacía extensiva a aquéllos que conseguían la libertad por vía de fuga, como fue el caso de Pere Sansó ${ }^{21}$ en 1596 y Miquel Salvà, en $159 .^{22}$

$\left.5^{\circ}\right)$ Lo más habitual es que la ayuda a cada cautivo fuera de 50 libras y en algunos casos de 25 . Siempre que se otorga ayuda a alguien liberado por fuga ésta es de 25 libras.

$\left.6^{\circ}\right)$ Se da una no despreciable presencia de rescatados originarios de Pollença. Además del citado Jeroni Vicens (1596), aparecen también en 1599 Joan Garriga y una mujer de la que no consta el nombre.

Contamos para mediados del siglo XVII, concretamente entre el 12 de enero de 1650 y el 12 de febrero de 1653, con la documentación relativa a las promesas de rescate tramitadas por cuenta de la manda pía de Francesc de Verí, un total de 48. De su análisis se puede concluir:

$1^{\circ}$ ) Se tiene en cuenta la preferencia de los menores de edad, determinándose el valor del recate de los menores de edad en 3001 . y de los mayores en $125^{23}$. Esta distinción la encontramos en otros casos como es el de la ayuda para el rescate de Josep Cugullada, de Alcúdia, que se establece en 300 1. si se hace efectivo antes de que cumpla 18 años y en 100 si se hace transcurrida dicha edad $^{24}$. Idéntica condición se establece con relación al rescate de Miquel Sastre ${ }^{25}$,

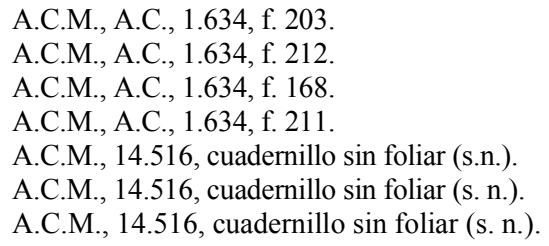


Agustí Avellàa ${ }^{26}$, Miquel Fons ${ }^{27}$ y Agustí Buyrà, hijo del patrón, también cautivo Antoni $^{28}$. Se trata de algo habitual. Así, por ejemplo, para el caso de los rescates de sicilianos los menores de edad, mujeres y trabajadores de sectores especializados, como eran los patrones, su importe era superior ${ }^{29}$.

$2^{\circ}$ ) Por lo que respecta a los lugares de nacimiento de los beneficiados de la ayuda, además del citado Josep Cugullada, aparece otro habitante de Alcúdia receptor de la ayuda para su rescate, Bartomeu Socies, así como uno de Llucmajor, Antoni Salvà ${ }^{30}$ y siguiendo las instrucciones de la obra pía- de Mateu Vila, de Pollença. En el resto de casos, no se determina su localidad de origen.

$\left.3^{\circ}\right)$ La ayudas al rescate para personas adultas a cuenta de esta manda pía son habitualmente de 100 11., en algunos casos de 125, aunque de mayor cantidad para los casos de rescate de patrones de barcos como son los casos de las 1501. destinadas al rescate de Antoni Llàmbies ${ }^{31}$, las 200 destinadas al rescate de cada uno de los siguientes patrones: Pedro Llorens ${ }^{32}$, Agostino Grisso ${ }^{33}$, Joan Serra ${ }^{34}$, Francesc Avellà ${ }^{35}$, Miquel Avellà ${ }^{36}$, Lluis Soler ${ }^{37}$, Antoni Francolí ${ }^{38}$, Antoni Buyrà $^{39}$ y Miquel Fàbregues ${ }^{40}$, todos ellos patrones de barco. Contrasta este mayor valor del rescate de patrones con el de marineros, a los cuales se concede una ayuda de 100 l., igual a las personas no ligadas al oficio de la mar $^{41}$.

$4^{\circ}$ ) Para aquellos casos en que se pedía un recate mayor, ya fuera por la supuesta riqueza del cautivo o su condición de eclesiástico, la cantidad aportada para el rescate era también mayor. Así se dieron 140 1. para el rescate de Jacint Vives, el cual parece que pagaba el rescate parcialmente con el envío de

26 A.C.M., 14.516, cuadernillo sin foliar (s. n.).

27 A.C.M., 14.516, cuadernillo sin foliar (s. n.).

28 A.C.M., 14.516, cuadernillo sin foliar (s. n.).

29 Bonaffini, Sicilia e Tunisia nel secolo XVII, citado por Martínez Torres, Prisioneros de los infideles, p. 35.

30 A.C.M., 14.516, cuadernillo sin foliar (s. n.).

31 A.C.M., 14.516, cuadernillo sin foliar (s. n.).

32 A.C.M., 14.516, cuadernillo sin foliar (s. n.).

33 A.C.M., 14.516, cuadernillo sin foliar (s. n.).

34 A.C.M., 14.516, cuadernillo sin foliar (s. n.).

35 A.C.M., 14.516, cuadernillo sin foliar (s. n.).

36 A.C.M., 14.516, cuadernillo sin foliar (s. n.).

37 A.C.M., 14.516, cuadernillo sin foliar (s. n.).

38 A.C.M., 14.516, cuadernillo sin foliar (s. n.).

39 A.C.M., 14.516, cuadernillo sin foliar (s. n.).

40 A.C.M., 14.516, cuadernillo sin foliar (s. n.).

41 Son los casos de Angelo Mandil, dos marineros llamados Joan Puig, Josep Moner, Carles Serra, Joan Abram (A.C.M., 14516, Joan Baptista Darder (A.C.M., 14516, cuadernillo sin foliar (s. n.). 
mercancías por su cuenta, ${ }^{42}$. Por su parte se destinaron 300 1. para el rescate de los religiosos Guillem Llull, dominico, y Antoni Nicolau, franciscano ${ }^{43}$.

\section{A MODO DE CONCLUSIÓN}

El caso que acabamos de exponer es un ejemplo de la multitud de caras con que se nos presenta la espiritualidad durante el Antiguo Régimen y a la vez de como los rasgos esenciales del propio Antiguo Régimen influyen en la espiritualidad. Un rasgo de esa larga época es la conciencia de pertenencia a un grupo determinado. De ahí las condiciones de la obra pía en el sentido de que los miembros de la familia Verí fueran preferidos a cualquier otro cautivo por redimir, incluyendo dentro de la familia a los criados. Es en este aspecto muy significativo que se llegue a afirmar que los criados forasteros, no mallorquines, tengan preferencia sobre cautivos mallorquines. Se trata de un ejemplo de cómo se explicitaban las fidelidades en esa época. La casa, incluía los criados, estaba por encima de otras fidelidades. En segundo lugar, los mallorquines serían preferidos a los forasteros. La patria así, en el sentido antiguoregimental del término, se constituía -en este y otros casos- como un segundo nivel de fidelidad ${ }^{44}$. La referencia a que en tercer lugar se procediera a rescatar a cautivos originarios de la Corona de Aragón es sintomática de la mentalidad de este miembro de la élite regnícola en ese momento concreto, pues en época medieval el concepto Corona de Aragón, como se deriva de los últimos estudios de A. Mas, era sumamente rara, especialmente es ese tipo de documentación ligada a la vida privada. De toda manera la trascendencia práctica de esa mención debió ser mínima por lo que se deriva de los libros de administración de la obra pía y los nombres de los rescatados o seleccionados por rescatar. Parece obvio que este orden de prelación, incluidos los cautivos originarios de Pollença, se corresponde poco con el carácter universal de la Iglesia Católica y de la redención de Cristo, a la cual se hacía referencia en el propio documento constituyente de la obra pía, constituida se decía, en record de Crist que ab sa preciosissima sang redimí los homens de la captivitat del pecat y esclavonia del dimoni Se trata de una disfunción no exclusiva del Antiguo Régimen. En todo caso este hecho debe contemplarse acompañado de otro que no podemos olvidar: la insistencia del testador en el

42 A.C.M., 14.516, cuadernillo sin foliar (s. n.).

43 A.C.M., 14.516, cuadernillo sin foliar (s. n.).

44 Para una visión del concepto Patria en el Reino de Mallorca vid., Mas, Llengua, terra, patria $i$ nació. 
hecho de que la obra pía constituida debía dedicarse a la redención de cautivos y no a otro fino institución de la Iglesia, fuera cual fuera.

La segunda disfunción que resaltar es la derivada de lo explicitado por el testador en la manda pía y la ejecución de la misma. La voluntad del difunto no se ejecuta al pie de la letra, singularmente por lo que se refiere a los aspectos logísticos y ceremoniales, ciertamente complejos. Tampoco debemos olvidar que el contacto con el musulmán estaba en ocasiones prohibido, incluso para el rescate, por parte de la Corona o sus agentes en el Reino. En este sentido es bien explícita la carta que con fecha 24 de agosto de 1581 remitió el Virrey de Mallorca a Felipe II:

V. M. me tiene mandado en sus Reales Instrucciones que no conceda licencias ni salvoconductos para Argel ni otras tierras de enemigos por los inconvenientes que se pueden seguir... y porque con esta ocasión me hacen grande instancia de licencia para rescatar muchas personas principales que allí hay cautivos de diversas partes y mallorquines que cada día cautivan y algunos peligran de renegar por no podellos rescatar, suplico a V. M. sea servido mandar que para este efecto ahora y quando se oferesca ocasión pueda dar dicha licencia con que se poría haver servido a V. M. teniendo avisos de lo que en Argel pasa sin costa alguna, pues yo no he de usar dello sino en caso que se haga servicio a V. M. y beneficio de este Reyno. ${ }^{45}$

De cualquier modo, el objetivo de la manda pía parece que se cumplió, aunque metamorfoseado. El capital destinado a su financiación se vehiculó singularmente en forma de ayudas al rescate que se entregaban a familiares de los cautivos seleccionados. Desde este punto de vista el legado Verí no era irrelevante, tanto por su larga duración (funcionó como mínimo hasta bien entrado el siglo XVIII) como por las cantidades que se destinaban a cada beneficiario. La cantidad habitual era de 501 ., cuando las ayudas que para la misma finalidad se concedía de las limosnas de la Catedral era de cinco, lo que nos indica que estamos ante una obra pía gracias a la cual aumentó la cifra de rescatados.

Aunque se destinó dinero a menores de edad, no fue ni la mayoría ni un número elevado, de manera que en ese aspecto, como en el de las mujeres, no se cumplió la voluntad del testador que había establecido su prioridad para el rescate habida cuenta de su supuesto mayor peligro de renegar. De hecho, entre 1596 y fines de 1599 no aparece ningún menor de edad y sólo una mujer entre

45 Miguel Deyá, M., Manuel Oliver, "El Mediterráneo bipolar: el Reino de Mallorca en alarma la Orden de Malta en guardia", en La Orden de Malta, Mallorca y el Mediterráneo (Palma: Consell de Mallorca, 2000), 62. 
los receptores de ayudas de la obra pía y entre los receptores del período 16501653 no aparece ninguna mujer y sí cinco menores de edad (menos de 18 años) para el rescate de cada uno de los cuales se destinan 300 libras si son rescatados durante la minoría de edad y 125 si la habían rebasado. Debe tenerse en cuenta que el rescate de mujeres presentaba ciertas singularidades. En principio su número era menor al de los hombres. Además, cabe no olvidar su valoración por parte de las sociedades norteafricanas como sirvientas domésticas y en algunas ocasiones como concubinas o incluso como esposas ${ }^{46}$. En ese mismo período destaca el mayor importe de las ayudas a patrones, para el rescate de los cuales -en un panorama de enfrentamiento entre las dos vertientes del Mediterráneose requería por parte de los musulmanes un mayor importe.

Y es que la espiritualidad de los siglos XVI y XVII, amén de místicos, ascetas y teólogos, nos presenta una faz también más de ras de tierra y más impregnada de la difícil convivencia ente dos religiones que son dos civilizaciones.

\section{REFERENCIAS BIBLIOGRÁFICAS}

Bover, Joaquín M. Nobiliario Mallorquín. Palma: José J. de Olañeta, 1996.

Bonaffini, Giuseepe. Sicilia e Tunisia nel secolo XVII. Palermo-Sao Paulo: Ilapalma, 1984.

Deyá, Miguel, Oliver, Manuel, "El Mediterráneo bipolar: el Reino de Mallorca en alarma la Orden de Malta en guardia". En La Orden de Malta, Mallorca y el Mediterráneo, Palma, Consell de Mallorca- Orden de Malta, 2000.

Mas, Antoni. Esclaus i catalans. Esclavitud i segregació a Mallorca durant els segles XIV y XV. Palma: Lleonard Muntaner Editor, 2005.

Mas, Antoni. Llengua, terra, patria i nació. L'evolució de la consciència lingüistica $i$ etnocultural entre elscristians de l'illa de Mallorca (segles XIVXVII). Palma: Ed Documenta, 2020.

Martínez Torres, José Antonio, Prisioneros de los infideles. Vida y rescate de los cautivos cristianos en el Mediterráneo musulmán (siglos XVI-XVII) (Barcelona, Ed. Bellaterra, 2004).

Planas, Antonio, "Los juristas mallorquines del siglo XVI", Memòries de l'Acadèmia Mallorquina d'EstudisGenealògics, Heràldics i Històrics, 10 (2000): 63-104.

Torreblanca, M. D (1999): "Redención de cautivos en la época de Felipe II". En Felipe II y su tiempo. Actas de la V Reunión Científica. Asociación Española 
de Historia Moderna, ed. José L. Pereira et Jesús. González, 211-218. Cádiz: Universidad de Cádiz- Asociación de Historia Moderna, 1999.

Miguel José Deyá Bauzá Universitat de les Illes Balears Edificio Ramon Llull, Cra. de Valldemossa, km. 7.5

07122 Palma de Mallorca (España) https://orcid.org/0000-0003-1268-4967 